University of Warwick institutional repository

This paper is made available online in accordance with

publisher policies. Please scroll down to view the document

itself. Please refer to the repository record for this item and our

policy information available from the repository home page for

further information.

To see the final version of this paper please visit the publisher's website. Access to the published version may require a subscription.

Author(s): Marilyn Hunt

Article Title: Progression and assessment in foreign languages at Key

Stage 2

Year of publication: 2009

Link to published version: http://dx.doi.org/10.1080/09571730902928086

Publisher statement: None. 


\title{
Progression and Assessment in Foreign Languages at Key Stage 2
}

\author{
Marilyn Hunt, University of Warwick
}

\begin{abstract}
Whilst the teaching of primary languages has been increasing steadily in response to the future entitlement for all key stage 2 (KS2) pupils aged 7-11 to learn a foreign language by 2010, there remain concerns about progression both within KS2 and through to secondary school and about how learners' progress is assessed. This paper presents findings on the issue of progression and assessment from case studies of a project funded by the then DfES (now DCFS) to evaluate 19 local authority (LA) Pathfinders in England piloting the introduction of foreign language learning at KS2, 2003-2005. Findings revealed that there was inconsistency across schools even within each local authority Pathfinder in the use of schemes of work and that assessment was generally underdeveloped in the majority of the Pathfinders. To set these findings in context it examines the issue of progression and assessment in foreign language learning in England. Finally it investigates the challenges English primary schools face in terms of progression and assessment in the light of the new entitlement and discusses implications for the future. This issue is particularly important as managing progression both within $\mathrm{KS} 2$ and through to KS3 is one of the key factors in determining the overall success of starting languages in primary school.
\end{abstract}

Key words: primary languages, progression, assessment

\section{Introduction}

This special edition marks the importance currently placed on foreign languages in the primary school. Readers of this journal will be fully aware that 2010 will see all key stage 2 (KS2) pupils (aged 7-11) in England entitled to learn a modern foreign language in normal curriculum time throughout the key stage. Whilst this development of the commitment to primary language learning should afford excellent opportunities and experiences for pupils, equally it will generate radical changes for many teachers and schools (both at primary and secondary level) who will need to 
develop and adapt practice to accommodate and capitalise on this curricular development.

The provision for foreign language learning in the primary sector has been growing steadily over the last decade in anticipation of this development. The most recent survey conducted in 2007 by the NFER for DCSF (Whitby, Wade and Schagen, 2008) reports that $84 \%$ of schools are now offering a language in class time to pupils in $\mathrm{KS} 2$ - a rise of $14 \%$ from 2006 . The number of schools who are meeting the entitlement fully across all year groups in KS2 has risen from 34\% in 2006 to 54\% in 2007. These are clearly positive developments considering earlier reports in 2004 that only $43 \%$ of primary children were currently learning a foreign language at KS2, either in class or as an extra-curricular activity, although the extent of this learning varied considerably with only $3 \%$ of primary children learning across all four years (Driscoll, Jones and Macrory, 2004). Hunt et al (2005) outlined key issues and challenges to be faced in providing this entitlement, for example curricular issues, modes of delivery, teacher supply and training and on-going training, teacher knowledge and qualifications (including phase specific pedagogy for secondary specialist teachers and subject specific pedagogy as well as linguistic knowledge, confidence and competence for primary non-specialist teachers), continuity and progression and transition from KS2 to KS3 (pupils aged 11-14).

The policy decisions in England to expand foreign language learning in the primary sector have particular implications for progression and assessment in language learning to work towards effective transition to the secondary sector and these create challenges for language teaching in both KS2 and KS3. This paper presents findings on the issue of progression and assessment from case studies of a project funded by the then DfES into the evaluation of 19 local authority (LA) Pathfinders in England who received additional funding in order to pilot the introduction of foreign language learning at KS2, 2003-2005. To set these findings in context it examines the issue of progression and assessment in foreign language learning in England. Whilst the findings relate to primary schools it is also important within this context to consider progression at KS3 as managing progression both within $\mathrm{KS} 2$ and through to $\mathrm{KS} 3$ is one of the key factors in determining the overall success of starting languages in primary school. Progression and assessment are vitally important to avoid the risk of repetition of work or the risk of disparate chunks of language being learnt rather than the development of skills, linguistic knowledge and the ability to apply this in a range of contexts. Finally it investigates the challenges English primary schools face in 
terms of progression and assessment in the light of the new entitlement and discusses implications for the future.

\section{Setting the context}

\section{Progression and assessment in language learning: defining the terms}

Progression in language learning within the key stage and across key stages signifies clearly planned schemes of work so that substantial repetition of the same material does not occur from year to year and key stage to key stage. If topics are revisited then these need to be revised, built on and extended linguistically and cognitively with increasing demand and challenges placed on learners so that pupils learn how to manipulate language in different situations as well as develop language learning skills. Progression refers to a broadening of contexts in content; a development of each of the four skills of listening, speaking, reading and writing as well as language learning skills; a deepening acquisition of linguistic knowledge and ability; and an expansion of cultural awareness. The National Curriculum Council non-statutory guidance for England and Wales (National Curriculum Council,1992: D2) suggested progression should be built into MFL planning in a number of ways: from concrete ideas to abstract, from simple aspects to complex, from specific themes to general, from factual topics to non-factual, from classroom experiences to the wider world, from familiar contexts to unfamiliar and from less controversial aspects to more controversial. The Key Stage 2 Framework for Languages (DfES, 2005) outlines learning objectives for MFL in all four years of KS2 with progression across five strands: oracy, literacy, knowledge about language, language-learning strategies and intercultural understanding. This clearly demonstrates that progression involves a complex range of elements and is far from linear; it requires considerable thought and planning to ensure progression is built into lesson plans, medium term plans and schemes of work.

Assessment is a tool to measure the progress achieved in pupils' learning (summative assessment or assessment of learning). It is also a means of providing feedback on progress and performance which is crucial in helping learners to make progress (formative assessment or assessment for learning). Important research on the value and potential of assessment for learning (Brooks, 2002; Black and Wiliam, 1998) as opposed to assessment of learning has led to much developmental work in assessment over recent years and has become a crucial part of the KS3 strategy. A renewed emphasis on positive, supportive feedback with constructive messages 
about specific ways to improve (target setting) has been adopted by schools in order to encourage, motivate and increase confidence and attainment.

The National Languages Strategy (DfES, 2003) set out the government's vision for languages in the $21^{\text {st }}$ century including policy decisions for an entitlement for languages at KS2 and a clear assessment opportunity by age 11 to reach a recognised level of competence on the Common European Framework and for that achievement to be recognised through a national scheme. This scheme, now known as the languages ladder, gives people credit for their language skills at all levels of competence and for all ages in a range of languages (DfES, 2004). The European Language Portfolio is another assessment tool developed as a Council of Europe initiative to provide an open-ended record of children's achievements in languages with details of languages known and used, how languages are learned, a selfassessment record of what a pupil can do in listening, speaking, reading, writing and intercultural understanding and space for examples of work. The up-dated portfolio (2006) includes reference to the languages ladder grades as well as the Common European Framework.

\section{Progression at secondary level}

The advent of GCSE developed in many cases into the teaching of language through a topic led approach. This, for some teachers and learners, restricted improvement in language competence and led to recycling topics from KS3 to KS4 without extending linguistic structures or any clear sense of progression. The nature of topics often proved demotivating and led to rote learning of set phrases rather than real linguistic understanding and competence. The National Curriculum for England (DfEE/QCA, 1999) signalled a move away from the topic approach to greater emphasis on the understanding and application of grammar in order to achieve greater progression.

Barnes and Hunt (2003) outlined the challenges encountered in achieving progression in MFL from year to year and across the key stages which have been highlighted by Ofsted, the official body for inspecting and regulating schools, over the last decade and reported as one of the main factors requiring attention in MFL teaching. As they point out, the longevity of this issue is indicated in the following quotations: 
'Within Key Stage 3, standards of achievement are better in Years 7 and 8 than in Year 9.' (Ofsted, 1995)

'Pupils make a good start in Year 7 but make less progress over the five years of compulsory secondary education than in most other subjects.'

(Ofsted, 1999)

'more attention to progression and to raising expectations of pupils' use of the foreign language is needed in planning'. (Ofsted, 2002a)

The most recent Ofsted report (Ofsted, 2005a) again mentions progression, but this time in relation to progression from KS2 to KS3. Ofsted recognises it as a strength in secondary MFL when senior managers and MFL heads of department acknowledge the provision of MFL in primary schools, and the need to secure effective continuity and progression between KS2 and KS3. They also view this issue as an area for development in secondary MFL and emphasise the need for all secondary schools to plan for ways to ensure MFL provision for pupils entering Year 7 builds on their prior experiences. They stress that head teachers, senior managers and governors of primary and secondary schools (as well as MFL heads of department and primary MFL coordinators) also have a key role because effective transition is dependent on important whole school decisions about the organisation and planning of the curriculum and of pupil grouping.

\section{Progression in primary schools}

Ofsted (2005b) in its inspection report of Pathfinder status schools piloting MFL programmes stated the need for all primary schools to develop schemes of work which demonstrate continuity and progression year on year, with due consideration given to the needs of pupils in mixed age classes. They recommended that this planning should take account of whole school curriculum provision, and show where learning a language links to other areas of the curriculum (for example literacy; personal, social and health education; citizenship and cultural development). The report suggested that learning a foreign language and language learning strategies can be built into the curriculum to deliver parts of other subjects such that the taught day can accommodate more opportunely the teaching and learning of a modern foreign language. The report declared that almost all schools need to develop assessment procedures to inform curriculum and lesson planning, and to ensure that all pupils make the best possible progress during the year, and year on year. 
Assessment in Year 6 should also inform the transition of pupils from primary to secondary schools.

\section{Primary ITT: Ofsted comments on progression and assessment}

The lack of emphasis on assessment and recording (amongst other areas) was highlighted by Ofsted (2003) in their inspections between September 2002 and June 2003 of the five providers of the MFL specialism in the primary courses who had introduced their training in 2001/02. Their conclusion was that the content of the specialist units was relevant and practical in all five providers, but with the absence of a statutory curriculum for MFL in primary schools and too little time, particularly in the one-year courses, for central training to cover everything of importance, some key topics had consequently either been omitted or given insufficient emphasis. One such topic had been assessment and recording, and continuity and progression at the end of KS2. Amongst the report's recommendations was that the various elements of the unit should combine so that trainees learn better how to assess and record pupils' progress in the subject, particularly in speaking and listening; and plan for progression over a year or a key stage. A more recently published survey (Ofsted, 2008) to evaluate the quality of initial teacher training (ITT) to prepare trainees to teach in primary schools recognised the increase in provision since the earlier report and the action planning resulting from their recommendations. However, they still advocated that providers of initial teacher training should 'ensure that training focuses on securing pupils' progression in language learning through effective assessment, including into secondary school' (Ofsted, 2008, p7).

Clearly from these commentaries progression and assessment are problematic areas in the teaching of languages in primary and secondary schools.

\section{Findings from eight Pathfinder case studies}

\section{Methodology}

The findings reported here form part of a larger study (Muijs et al, 2005) which investigated the 19 local authority Pathfinders in England which were piloting the introduction of foreign language learning at KS2 during the period 2003-5. Eight case studies were identified in order to explore how Pathfinders were operating and a total of 41 schools were included in the sample, including one special school, one specialist language college and one secondary school, not a specialist language college, but working on an outreach programme for MFL with seven primary schools. Case studies were selected according to the following factors: the identification of 
different basic models in the initial phase of data collection from the telephone interviews with LA officers and the Pathfinders' initial plans, and by sociodemographic and geographic diversity. The selection of schools reflected different socio-economic groupings, schools of different type and size, schools in different locations, that is, inner-city, rural, metropolitan, borough and schools which were performing or improving at different rates.

Three main methods were utilised to investigate the case: interviews with head teachers, teachers and pupils, lesson observations and collection of documentary evidence. Interview transcripts were analysed using theme analysis. The interviews enabled the development of categories and typologies and comparative analyses so that, 'instances are compared across a range of situations, over time, among a number of people and through a variety of methods' (Woods, 1996, p.81). The observation instrument contained a purely qualitative section, where the observer made detailed notes of everything which took place in the lesson and an initial analysis checklist based on the team's review of best practice in teaching languages. The data produced, therefore, support both qualitative and quantitative analysis. Documentary evidence included school Ofsted reports, post-Ofsted planning, PANDAs, LA Reports and School Improvement Plans to provide important contextual and background information about the schools, as well as minutes from meetings, project plans, materials and resources developed where available. These provided important information on the development and evolution of the project, and allowed qualitative judgements on the quality of materials produced. The information derived from these was triangulated with other data sources, to allow robust pictures of how the different Pathfinder models were working in practice in schools.

\section{Findings: progression in the practice of KS2 pathfinder schools}

This section refers to the use of national documents: the Key Stage 2 Framework (DfES, 2005) and QCA schemes of work (DfEE/QCA, 2000) which outline a clear structure of progression in language and skills. As the Pathfinder was a two year programme of activity there was insufficient evidence to measure progression fully.

Findings from the case study interviews with teachers revealed that there was inconsistency across schools even within each local authority pathfinder. A majority of schools were not using the QCA schemes of work and those who were did not follow a uniform approach to using them. In some instances 'visiting' teachers from 
the local secondary school or teachers employed to move from one primary school to another took charge of the language teaching and therefore some teachers were unsure as they followed the plans of the visiting teacher. Whilst the Key Stage 2 Framework had been piloted in some Pathfinder schools, in others teachers were unaware of the guidelines.

Some Pathfinders devised schemes of work for use across the Pathfinder containing differentiated activities and learning materials with an emphasis on progression. However, these schemes of work were not always fully developed throughout KS2. In two Pathfinders, the presence of an Advanced Skills Teacher (AST) for MFL led to the constant reworking of the schemes of work for the different years and in the light of national developments in order to avoid too much repetition and ensure progression. Where non-specialists were involved, the provision of such schemes of work and materials, which had previously been designed to match rising levels of difficulty to ensure progression, was highly beneficial in guiding pupils' learning.

In many instances, schemes of work were evolving as the Pathfinder progressed. Predominantly, languages were focused in Years 5 and 6, although in some Pathfinder schools, all four year groups, 3, 4, 5 and 6 were involved, in others just Year 3 and Year 4 or just Year 5 and Year 6. In many schools where language teaching had started in Years 5 and 6, the intention was to move the language further down the age range as it embedded itself in the curriculum. In creating a coherent scheme across the full key stage, schools recognised the need to modify current working and recognise different starting points as the learning programme developed throughout the school. However, this model of working backwards down the key stage had proved problematic, as both primary and secondary have had to change schemes of work each year. Where this had occurred, working up from Year 3 was often considered more practical, as progression could be developed.

Challenges in achieving progression across year groups were exemplified in one school where children in different years (Reception, Year 4 and Year 5) were receiving the same content - basic personal information plus colours, numbers, pets etc, but there was no overall strategy for progression from year to year. This problem resulted from staff moving between different year groups and limited staff expertise. Other schools likewise recognised the limitations of subject knowledge of their staff and therefore the difficulty in making language work more challenging for their pupils, especially in years 5 and 6 . 
There were particular challenges for schools where classes were arranged in vertical groupings, with combined year groups, for example, Year 3 and Year 4 taught together, or Year 5 and Year 6 . In some schools therefore, there were problems with continuity from one NC year to the next, particularly where vertically grouped classes in small, rural schools were concerned.

\section{Findings on assessment in the practice of KS2 pathfinder schools}

This section reports on the use of various assessment tools in MFL at KS2, the assessment conducted (both formative and summative) and recording evidence of assessment.

\section{Assessment tools}

In the majority of Pathfinders, head teachers generally seemed unaware of the Languages Ladder and even amongst teachers there was confusion or scant knowledge of expected levels, although some schools acknowledged the need for a better formal record of pupils' attainment levels.

In one Pathfinder, it was anticipated that the Languages Ladder would have some impact, but interviewees had little knowledge of the proposed scheme, although they assumed they could adapt existing schemes of work to fit. In another Pathfinder, the specialist language college was planning to implement the Languages Ladder and it was hoped that this would engage some of the local primaries and entice more secondary schools to get involved by becoming the accredited centres for their area. In another Pathfinder one school cluster had decided not to trial the Languages Ladder as three out of the four schools had significant staffing changes. Whilst in one Pathfinder the LA reported the Languages Ladder was being used, in reality, none of the teachers interviewed mentioned using it to measure pupils' progress. This dissonance between LA reports of how schools are assessing and teachers' own accounts raises questions as to communication between parties, lack of understanding of what is/could/should be happening and the timescale between planning and implementation.

Some Pathfinders were using the European Languages Portfolio (ELP); in one Pathfinder this has been tailored to fit the multilingual delivery model. However, use of the European Languages Portfolio was not always used consistently across the 
pathfinder. For example, in one Pathfinder it was being used in only one of the five case study schools.

\section{Formative and summative assessment}

The findings from the evaluation of the Pathfinders revealed that assessment was generally underdeveloped in the majority of the Pathfinders. Teachers were more concerned about developing confidence in teaching language and in enthusing their learners about languages rather than in assessing learners. This reflects the early stages in the development of language teaching at primary level and the lack of development of formalised procedures. In a later small scale research study, Bolster et al (2004) also found that there was no formal assessment for Year 6 ELL pupils at the time of the study and that in the primary school there was a feeling that assessment might 'kill' the fun at primary level whilst in the secondary schools there was a concern about the lack of (recorded) assessment.

In schools where there was no quantitative measure of attainment, the qualitative evidence was often extensive, from performance in assemblies to realisation that some less confident children had 'come out of their shells.' Assessment was seen more to be a question of monitoring by checking how pupils had retained knowledge from previous lessons through the general recapitulation questions at the beginning of each lesson.

In some Pathfinders objectives were clear and assessment was built into the scheme of work with targets for Year 6 or suggestions for an end-of-unit activity as a useful opportunity for the assessment of pupils' progress. However, even where assessment formed part of the local authority scheme of work and devised units, monitoring of pupil progress was patchy and varied across the year groups and across the case study schools within Pathfinders. In some Pathfinder schools no assessment was conducted, whilst in others a range of assessment strategies were used. In the main, the emphasis was on informal monitoring of work in class, observing pupils' participation, listening to what pupils are saying and monitoring verbal output, checking on pupils' understanding through the use of whiteboards and 'show me' techniques. Again this confirmed teachers' interpretation of the lack of importance of assessment in language learning. However, some formative assessment was evidenced in monitoring children's ability to answer the questions posed with feedback to pupils' responses to questions, sharing NC levels with pupils and explaining what a particular level represents, looking at pupils' workbooks/ 
worksheets to provide feedback comments and self-assessment 'I can do....' statements as an on-going process. In a minority of schools there were examples of summative assessment in end of section assessments and half- termly or termly assessments. One visiting teacher kept a personal record of children's work, with a view to feeding back to class teachers which pupils were particularly able and which pupils were struggling to enable the teacher to write a comment about French on pupils' annual reports.

In four case study Pathfinders teachers admitted that little or no attention had been paid to measuring pupils' progress and there was scant evidence of assessment strategies or procedures. In two of these no formal assessment took place. In the Pathfinder study many head teachers said this would be part of their future development plan but generally there was some resistance to the notion of an imposed scheme and the worry that introducing assessment would change the whole nature of the experience. Teachers often justified the lack of action on assessment as anxiety about adding to teachers' workload and the need to avoid putting too much pressure on staff and pupils.

Where visiting teachers were involved, be it from the specialist language college, secondary school or a peripatetic teacher, teachers mainly relied on these to make formal assessments at the end of Year 6.

One example of peer assessment was observed where pupils gave PowerPoint presentations of descriptions and opinions of celebrities. Clear assessment criteria were discussed with the pupils beforehand, assessment sheets were handed out and explained and after each presentation there was whole class discussion in English about the merits of the work and in the plenary discussion of how to get a better mark. This lesson was taught by a secondary colleague and reflected the assessment for learning agenda, currently an important element of the KS3 strategy.

\section{Recording evidence of progression}

The picture regarding recording was equally diverse and patchy. Where there had been little emphasis (if any) on assessment, head teachers thought that evidence could be extracted from planning, French books and comments on reports to indicate progress, but nothing more formal. In many schools reading and writing were minimal and no marks were given for work and therefore no marks recorded. 
In a number of Pathfinders recording evidence of progression was achieved through pupil assessment folders including written work, tick box, and self-assessment sheets. Some schools planned a portfolio to record on-going achievements with a view to them taking this on to secondary school, or completed forms annually to record what had been covered.

One Pathfinder had developed good practice of recording evidence of progression through profile cards with child friendly 'I can' statements, 'What we've learnt this term', 'What we need to work on' and information on how to progress from one level to another. Children received a certificate at the end and stood up in assembly. Another had developed pupil's self-assessment sheets to record progress at different levels in Listening, Speaking, Reading, Writing and Awareness. In one case the self assessment sheet was extended to include a 'My witness' column where a peer or the teacher could confirm the self assessment.

Very little mention was made of the use of NC levels, although in some cases there was evidence of some development in this area with training carried out centrally through the Local Authority. One Pathfinder developed an assessment sheet providing a guide up to level 4 in Speaking, Listening, Reading and Writing, but no record of marks was kept.

There were difficulties for peripatetic teachers. For example, one visiting teacher who taught 19 classes found it difficult to know all the pupils' names; she could give information regarding bandings of ability but she would need assistance from the class teacher for names in recording assessment levels later.

One school had a well developed assessment and recording system whereby the coordinator kept records of assessment for all pupils and the pupils all had individual portfolios displaying their own work. A school portfolio contained pupils' self evaluation sheets which listed items with columns: 'I can', 'I can with help', 'I've forgotten' and evidence of pupils' work at different levels. There was clear evidence of progression of what Year 6 had achieved this year compared to last year's Year 6 . In this school assessment begins orally in lower KS1 and assessment is written into the new units through the activities. In the future they planned to record pupil interviews to be up-loaded onto the secondary school's website. 
In some cases, even where assessment opportunities were provided in schemes of work or where language awards were used, pupils on the whole did not report that their work/performance was 'marked' in any way other than general encouragement to the class as a whole. Pupil interviews demonstrated that they would like to know how they were progressing and would appreciate feedback on how to improve and make progress as in many lessons teachers tended to give general praise to the class as a whole.

Pupils in one school said they were given a 'special mention' and a sticker for French at the end of the week. Some children had a chart in the classroom and once this was complete, they received a commendation. They were not awarded marks as such and writing was limited to labelling shapes or matching pictures and words. In another school pupils said there were no marks for French, because written work was not done in French, nor tests, although there were worksheets, mainly for colouring type tasks. House points were awarded if teams did well in oral games.

\section{Discussion and future implications}

Coherent schemes of work form the basis of effective planning and can play a significant role in consistent and effective primary languages provision by contributing to learners' progression in the subject and teachers' confidence when faced with, for example, staffing changes or illness. A scheme of work is particularly beneficial for primary languages:

- It helps to counteract to some extent a teacher's perceived or actual lack of subject knowledge and competence

- It is important for pupils' progression and assessment (between years and key stages, across schools and across authorities).

It benefits the subject's coherence and status, especially to avoid repetition when pupils work in vertical groupings. Schools should therefore be encouraged to base their planning on schemes of work which include assessment opportunities and which are based on appropriate primary pedagogy and not on KS3 schemes of work. De Silva and Satchwell (2004) provide advice for primary teachers embarking on a foreign language programme on planning themes and topics and a scheme of work to include progression in linguistic and learning skills and grammar. However, schemes of work will only work effectively when teachers have adequate subject knowledge and pedagogy. Supportive training and networks are crucial in the development of primary language teachers as progression in learning is very much dependent on teacher expertise and confidence. 
Although some schools had well developed assessment practices, generally assessment was patchy and under developed and depended in the main on informal monitoring and observation rather then any planned processes. Even where positive attitudes to foreign languages exist, there seems to be some reluctance to assess pupils. Assessment is viewed as an additional burden for primary teachers and a threat to pupils' enjoyment of languages. Clearly, further development in this area is vital. It would be helpful for teachers to receive training in an understanding of NC levels to aid their planning so that teaching is developed beyond word level to include basic structures, verbs and connectives to move pupils' learning forward. Training in assessing languages and applying NC levels would also be beneficial so that pupils receive individual feedback on their performance as in other subjects. Further development of methods of recording progression, for example profile sheets, would assist in formalising this process. Although the government in its promotion of languages wants pupils to enjoy languages there is also an emphasis on sustained language learning. There is an implicit expectation that primary languages will improve both take-up and results at KS4. At the time of the Pathfinder evaluation the Languages Ladder was in its infancy. Case studies of the successful use of the recognition scheme at primary level are now available on the Asset languages website, but we are yet to see its widespread use and the implications this has at secondary level.

It is vitally important to build effectively on pupils' achievements as they transfer to secondary school. One of the explicit objectives of the KS3 strategy is to improve progression across the key stages. However, an Ofsted report (2002b) noted that continuity in the curriculum and progression in learning as pupils move from primary to secondary schools are longstanding weaknesses. If difficulties arise in NC statutory core subjects (English, Mathematics and Science), it is easy to imagine the challenges facing MFL when pupils transfer to a secondary school from a range of feeder primary schools where 'entitlement' potentially means great diversity in language provision in time allocation, teaching quality (both subject knowledge and pedagogic expertise), and even the language studied. A simple system of recording evidence of work covered and what has been achieved at primary school would help inform secondary colleagues so that work is not repeated and challenge is built in at all levels for learners in Year 7. 
Language learning in the primary phase will undoubtedly have an impact on the secondary curriculum and secondary MFL teachers also need to plan carefully to adjust practice in KS3 and especially in Year 7 where they will need to cater for a wide diversity of prior knowledge and skills. Tucker and Donato (2003) describe a similar challenge for teachers in the USA to develop the cognitive and academic language proficiency of their students following a successful foreign language programme in elementary school. It is particularly important that the two curricula for the top of KS2 and early KS3 are aligned, both in terms of content and teaching style. This is especially so in Year 6 and Year 7 where a coherent approach and mutual understanding are crucial to progression. The current emphasis on integrated language learning at KS2 helps to embed languages across the curriculum and leads well into the potential for more flexibility in the revised curriculum at KS3 (QCA, 2007) and innovative work in CLIL at secondary level. Secondary teachers will need to develop further strategies to cater for Year 7 mixed-level groups with a wide diversity of prior knowledge and skills to maintain motivation and achieve progression and continuity through effective differentiation. Boodhoo (2005) emphasizes the role of initial teacher education in developing training which examines similarities and differences in teaching and learning styles in KS2 and KS3, and incorporates an integrated approach to the development of knowledge about literacy, language, MFL and cultural and intercultural understanding (across KS2 and KS3) as well as development of knowledge regarding suitable assessment methods for primary languages which can add to more meaningful transfer data between KS2 and KS3 schools.

This paper has concentrated on progression within $\mathrm{KS} 2$, but this needs to be viewed within the 7-14 languages curriculum and therefore continuity and progression to the secondary phase is key to achieving and maintaining pupil motivation for languages as well as attainment. Hunt et al (2008) explore the issue of transition in detail and find a distinctly diverse picture with regard to primary MFL provision, choice and continuity at secondary level, information transfer and transition arrangements and conclude that much work needs to be done to tackle the issue of transition and maintain continuity and progression. This is an aspect of the primary languages development which could be a serious hindrance to successful implementation and continued sustainability. Managing progression both within KS2 and through to KS3 is one of the key factors in determining the overall success of starting languages in primary school. 


\section{References}

Asset Languages. Available online at:

http://www.assetlanguages.org.uk/casestudies/default.aspx (accessed 15 November 2007).

Barnes, A. and Hunt, M. (2003) Effective assessment in MFL (London, CILT)

Black, P. and Wiliam, D. (1998) Inside the black box: raising standards through classroom assessment, Phi Delta Kappan, 10. Available online at: www.pdkintl.org/kappan/kbla9810.htm (accessed 11 November 2008).

Bolster, A., Balandier-Brown, C. and Rea-Dickens, P. (2004) Young learners of modern foreign languages and their transition to the secondary phase: a lost opportunity?, Language Learning Journal 30, 35-41

Boodhoo, N. (2005) Connecting Key Stage 2 and Key 3 Foreign Language Provision: Developing Understanding for Initial Teacher Education - Case Studies of Current Practice. Available online at: http://www.ttrb.ac.uk/viewArticle.aspx?categoryld=14537\&taggingType=4\&co ntentld=11389 (accessed 25 October 2006).

Brooks, V. (2002) Assessment in secondary schools: the new teacher's guide to monitoring, assessment, recording, reporting and accountability. (Open University Press).

Council of Europe (2006) European Language Portfolio. Available online at: http://www.nacell.org.uk/resources/pub cilt/portfolio.htm (accessed 9 July 2008).

De Silva, J. \& Satchwell (2004) A flying start! Introducing early language learning. (London, CILT)

DfEE/QCA (1999) The National Curriculum for England. (London, DfEE/QCA).

DfEE/QCA (2000) Modern foreign languages. A scheme of work for key stage 2. (London, DfEE/QCA).

DfES (2003) Languages for All: Languages for Life. A strategy for England. (Nottingham, DfES publications).

DfES (2004) The Languages Ladder. Steps to success. Available online at: http://www.dfes.gov.uk/languages/uploads/Ladder.pdf (accessed 9 July 2008).

DfES (2005) The Key Stage 2 Framework for Languages. (Nottingham, DfES).

Driscoll, P., Jones, J. and Macrory, G. (2004) The provision of foreign language learning for pupils at Key Stage 2. Available online at: http://www.dfes.gov.uk/languages (accessed 24 June 2006).

Hunt, M., Barnes, A., Powell, B. Lindsay, G., Muijs, D. (2005) Primary Modern 
Foreign Languages: an overview of recent research, key issues and challenges for educational policy and practice, Research Papers in Education, 20 (4), 367-385

Hunt, M., Barnes, A., Powell, B., Martin, C. (2008) Moving on: the challenges for foreign language learning on transition from primary to secondary school, Teaching and Teacher Education, 24(4), 915-926

Muijs, D., Barnes, A., Hunt, M., Powell, B., Martin, C., Arweck, E. Lindsay, G. (2005) Evaluation of the Key Stage 2 language learning pathfinders. London, DfES. Available online at: http://www.dfes.gov.uk/research/data/uploadfiles/RR692.pdf. (accessed 15 November 2006).

National Curriculum Council (1992) Modern Foreign Languages: non-statutory guidance for England and Wales. (National Curriculum Council).

Ofsted (1995) Modern Foreign Languages: a review of inspection findings 1993/4. (HMSO).

Ofsted (1999) Modern Foreign Languages: a review of inspection findings 1997/1998. (HMSO).

Ofsted (2002a) Secondary Subject reports 2000/01. Available online at: www.ofsted.gov.uk (accessed 11 December 2006).

Ofsted (2002b) Changing schools - an evaluation of the effectiveness of transfer arrangements at age 11. Available online at: http://www.ofsted.gov.uk/assets/2563.pdf (accessed 11 December 2006).

Ofsted (2003) Primary modern foreign languages in initial teacher training: A survey. Available online at: http://www.ofsted.gov.uk/assets/3424.doc (accessed 29 October 2007). Ofsted (2005a) Modern Foreign Languages in Secondary Schools. Available online at: http://live.ofsted.gov.uk/publications/annualreport0304/subject_reports/secon dary/mfl.htm (accessed 29 October 2007).

Ofsted (2005b) Modern Foreign Languages in Primary Schools Document reference number: HMI 2431 Available online at: http://live.ofsted.gov.uk/publications/annualreport0304/subject_reports/primar y/primarymfl.htm (accessed 29 October 2007).

Ofsted (2008) Primary languages in initial teacher training. HMI 070031. Available online at: http://www.ofsted.gov.uk/Ofsted-home/Publications-and- 
research/Education/National-strategies/Primary/Primary-languages-in-initialteacher-training/(language)/eng-GB (accessed 3 September 2008)

QCA (2007) The National curriculum at key stages 3 and 4. Available online at:

http://curriculum.qca.org.uk/key-stages-3-and-4/index.aspx (accessed 10 July 2008)

Tucker, G. R. \& Donato, R. (2003) Implementing a district-wide foreign language program: A case study of acquisition planning and curricular innovation, in D. Tannen \& J. E. Alatis (Eds) Georgetown University Roundtable on Languages and Linguistics 2001, Linguistics, Language, and the Real World: Discourse and Beyond. (Washington, DC: Georgetown University Press), 178-193.

Whitby, K., Wade, P. and Schagen, S. (2008) Language learning provision at Key Stage 2: Findings from the 2007 survey. Available online at: http://www.dcsf.gov.uk/research/data/uploadfiles/DCSF-RBX-09-08.pdf (accessed 14 August 2008)

Woods, P. (1996) Researching the Art of Teaching: Ethnography for Educational Use. (London: Routledge). 